\title{
POLÍTICAS PÚBLICAS PARA A FORMAÇÃO DOCENTE: SABERES E PRÁTICAS DA DOCÊNCIA
}

\author{
Tania Micheline Miorando ${ }^{1}$, Ionice da Silva Debus ${ }^{2}$, Valeska Maria Fortes de Oliveira ${ }^{3}$
}

\begin{abstract}
Resumo: $\mathrm{O}$ artigo que ora apresentamos tem por objetivo mostrar a formação de professores, discutindo a qualificação como política de apoio à condição profissional. Os argumentos deste estudo já foram considerados principalmente por pensadores da Educação como Tardif (2012), Tardif e Lessard (2011), Nóvoa (1992; 1995; 2009) e Pimenta e Anastasiou (2010). Metodologicamente, ancoramos as considerações que trazem em narrativas de professores-cursistas do curso de Pedagogia/Parfor, Univates, que corroboram suas teses. As narrativas de formação amparam-se em autores que já versam profundamente nesta área ao tratarem das discussões que fazem-se pauta na formação de professores sobre a profissionalização docente e o desenvolvimento profissional: Delory-Momberger (2008), Chène (2010) e Josso (2004). A isso soma-se compreender as políticas que regem o aprimoramento dos estudos, possibilitando que se viabilize metas, índices e intenções de qualificar a Educação no Brasil, em nome da profissionalização do professor, por leituras e estudos da legislação nacional (BRASIL, 1971; 1996; 2007; 2014). Por fim, ressaltamos que a docência tem saberes pertinentes à profissionalização docente e está em contínuo processo de formação, cujos saberes profissionais, experienciais e pessoais se agregam ao longo da vida.
\end{abstract}

Palavras-chave: Formação de Professores. Políticas de formação docente. Saberes docentes.

\section{PUBLIC POLICIES FOR TEACHER EDUCATION: KNOWLEDGE AND TEACHING PRACTICES}

\begin{abstract}
The present article aims to show the formation of teachers, discussing the qualification as a policy to support the professional condition. The arguments of this study have already been considered mainly by educational thinkers, such as Tardif (2012), Tardif and Lessard (2011), Nóvoa (1992; 1995; 2009) and Pimenta and Anastasiou (2010). Methodologically, we anchor the considerations that bring in narratives of teachers-students of the course of Pedagogy/Parfor, Univates, that corroborate their theses. The training narratives are based on authors who are already deeply involved in this area when discussing
\end{abstract}

1 Doutoranda em Educação. Mestre em Educação. Professora na Universidade do Vale do Taquari Univates. Email: tmiorando@gmail.com

2 Pedagoga. Doutora em Educação pela Universidade Federal de Santa Maria - UFSM. Tutora do Curso de Pedagogia EaD/UFSM. Email: nicedebus@hotmail.com

3 Professora Titular do Departamento de Fundamentos da Educação da Universidade Federal de Santa Maria - UFSM. Coordenadora do Grupo de Estudos e Pesquisas em Educação e Imaginário Social GEPEIS/UFSM. Email: vfortesdeoliveira@gmail.com 
these themes to that take a place in teacher training on teacher professionalization and professional development: Delory-Momberger (2008), Chène (2010) and Josso (2004). To this end, it is necessary to understand the policies that govern the improvement of the studies, enabling the achievement of goals, indexes and intentions to qualify Education in Brazil, in the name of teacher professionalism, through readings and studies of national legislation (BRASIL, 1971; 1996, 2007, 2014). Finally, we emphasize that teaching has relevant knowledge for teacher professionalization and is in continuous process of formation, whose professional, experiential and personal knowledge are added throughout the life.

Keywords: Teacher Training. Teacher training policies. Teacher knowledge.

\section{Formação e práticas: saberes para uma profissão}

Pensar que é a escola que vai ensinar a aprender talvez seja o mais equivocado dos pensamentos que um professor possa levar para si durante sua atuação profissional. E mais, mostra que a sua formação não o fez mexer com essa forma de considerar os saberes que trazemos desde os nossos primeiros dias de vida!

Este artigo traz provocações já consideradas por pensadores da Educação, como Tardif (2012), Tardif e Lessard (2011), Nóvoa (1992; 1995; 2009) e Pimenta e Anastasiou (2010). Das considerações que trazem, buscamos narrativas de professores-cursistas do curso de Pedagogia/Parfor, Univates, que corroboram suas teses. As narrativas de formação amparam-se em autores que já versam profundamente nesta área ao tratarem das discussões que fazem-se pauta na formação de professores sobre a profissionalização docente e o desenvolvimento profissional: Delory-Momberger (2008), Chène (2010) e Josso (2004). A isso soma-se compreender as políticas que regem o aprimoramento dos estudos, possibilitando que se viabilize metas, índices e intenções de qualificar a Educação no Brasil, em nome da profissionalização do professor, por leituras e estudos da legislação nacional (BRASIL, 1971; 1988, 1996; 2007; 2014).

Das experiências a se traduzir dos estudos para este artigo, nos manifestamos desde a sala de aula, na atuação com a formação inicial de professores. Os estudos que aportam esta temática têm tratado acerca dos saberes envolvidos nesta fase da formação profissional, pela perspectiva dos professores formadores, corresponsáveis pela formação dos docentes da escola básica. Entendemos que a responsabilidade em divulgar o que pensamos está fortemente alicerçado pela incumbência em levar os princípios que acreditamos para além dos espaços de sala de aula, para artigos como este, por exemplo.

Metodologicamente os estudos pautaram-se em base qualitativa, tomando as narrativas de formação acerca dos saberes da profissão docente dos estudantes das licenciaturas e futuros professores, bem como dos docentes formadores destes. A análise deu-se por considerar o imaginário social (CASTORIADIS, 1982) que paira nos dizeres dos professores, assim pressupondo seus pensares, anunciando-os em suas falas. A interpretação que fizemos deu importância aos diálogos que aconteceram, deixando em evidência a experiência hermenêutica, que renuncia "à ideia de uma verdade última e incondicionada" (FLICKINGER, 2010, p. 2). 
Para tanto, na construção efetiva dos dados, fizemos a escolha por utilizar as narrativas de formação, visto que "relativamente à narrativa de vida, presume-se que a narrativa de formação apresente um segmento da vida: aquele durante o qual o indivíduo esteve implicado num projeto de formação" (CHÈNE, 2010, p.132). Assim, permite-se que o autor da formação seja também autor de um discurso sobre sua formação, tendo acesso, pela palavra, ao sentido que dá à sua formação e a si próprio.

No transcorrer deste artigo abordaremos as questões de uma política governamental que pôde favorecer a formação de professores, como professores-cursistas ${ }^{4}$, de uma turma de Pedagogia - Parfor, que, ao estarem em sala de aula, sem que dependessem de seus salários para quitar as mensalidades em uma universidade paga para a formação, qualificaram seu fazer docente. Intrinsecamente, outro ponto abordado é a discussão curricular para a formação, conversando com pensadores da Educação.

\section{Saberes: a docência que se legitima em uma profissão}

Os saberes docentes, acionados pelos professores no cotidiano da sala de aula, legitimam o discurso que permite que se fale na docência como uma profissão. Ao assumir como um trabalho que exige um repertório de conhecimentos que precisam ser debatidos e pesquisados nos cursos de formação de professores, as instituições formadoras se veem implicadas em ações com os formadores e extensivas nesse ofício. Convém destacar que o campo de estudos conhecido como epistemologia da prática docente tem produzido uma série de reflexões significativas para que possamos pensar no trabalho docente e as respectivas exigências relacionadas à atual escola, à universidade e à sociedade como um todo.

A partir disso, outros estudos já constataram variados saberes necessários à profissão docente, tendo o próprio histórico da reflexão destes saberes ancorado no exercício dos professores da educação básica, sendo que alguns são compartilhados pelos docentes universitários também. Estes diferentes saberes foram elencados por Gauthier et al (2013), depois por Tardif (2012), os quais compartilham as pesquisas e debates sobre esta temática. Segundo os autores, podemos reconhecer:

- Os saberes da formação profissional (das ciências da Educação e da ideologia pedagógica): são os saberes profissionais e trata-se do conjunto de saberes construídos nas instituições de formação de professores. O professor e o ensino constituem objetos de saber para as Ciências Humanas e da Educação.

- Os saberes disciplinares: são integrados à prática docente através da formação (inicial e continuada), correspondem aos diversos campos do conhecimento e

4 Usa-se a nomenclatura "professor-cursista", adotada pela Capes, aos professores matriculados em um curso de formação docente, em respeito à função que já exercem nas escolas, para além de uma posição de estudantes em um curso de formação de professores. 
encontram-se integrados nas universidades, faculdades e cursos distintos, sob a forma de disciplinas. Estes, emergem da tradição cultural e dos grupos sociais produtores dos saberes.

- Os saberes curriculares: correspondem aos discursos, objetivos, conteúdos e métodos a partir dos quais a instituição escolar categoriza. Apresentam-se concretamente sob a forma de programas escolares, que os professores venham aprender a aplicar.

- Saberes experienciais: são os que os próprios professores, no exercício de suas funções e na prática de sua profissão, desenvolvem. Podem ser chamados também de saberes práticos. Mostram-se como específicos, baseados em seu trabalho cotidiano, brotam da experiência e são por ela validados. Incorporam-se à experiência individual e coletiva sob a forma de hábitus e de saber-fazer.

Uma vez identificados das práticas que nos levam a exercer a função docente, já não podemos mais alegar que instintivamente cumprimos a profissão. Há um campo legitimado que enuncia a manifestação das didáticas de sala de aula para o ensino e a aprendizagem que escolhemos agir. Mesmo impregnados pela intenção de ensinar, não nos basta o empirismo e as memórias (ABRAHÃO, 2010). As lembranças que trazemos de nossos professores, afinal, somamos em torno dos quinze anos em banco escolares, enriquecem nosso repertório, mas não justificam as metodologias que elegemos. A profissão exige uma formação que nos coloque a pensar o fazer docente.

No dizer de uma das professoras-cursista da Pedagogia/Parfor, Univates, sua trajetória no curso traduziu-se, em parte, na monografia final que narra seus saberes na escola que ainda atua. Agora, somando suas razões na defesa de uma Educação no Campo, manifestada pelos argumentos que se tornaram mais potentes, com mais vozes:

Para quem se interessar pela temática (educadores, estudantes de universidades e
outros), trago reflexões a partir da pesquisa, uma vez que as Escolas do Campo
também fazem parte do sistema educacional. Como aluna concluinte do curso
de Pedagogia do Plano Nacional de Formação de Professores - Parfor, sinto-me
instigada a compreender e refletir sobre questões específicas dessas escolas, por
estar tendo a oportunidade de atuar como gestora e educadora de uma Escola do
Campo (TATSCH, 2015, p. 11).

Talvez tivesse, antes mesmo de cursar a Pedagogia, tais razões por ter assumido a docência. Agora, entretanto, estão vigorosamente amarradas à pesquisa e um leque de autores que a sustentam em seus argumentos. Estar gestora desta escola a coloca em uma posição ainda mais referencial em sua comunidade. A ela consolida-se a figura da professora que é liderança na comunidade. O conjunto de seus saberes é reconhecido nos seus espaços de vida.

A seguir, trazemos para o debate a formação que se inicia precoce, no Ensino Médio. Colocamos em xeque a autorização em assumir períodos tão importantes da educação de uma criança, na vida e na escola, por um tempo de formação que divide- 
se em finalizar seu tempo de Educação Básica e assumir uma turma de crianças. Professoras tão jovens, estão "formadas" para a docência?

\section{Jovens Professores: aprender para si ou para o outro?}

Concordamos que a docência tenha sempre a incumbência de aprender (FREIRE,1998). Mas há tempos e etapas em fases de aprendizados que a vida proporciona maior deleite ou responsabilidade sobre o que aprendemos. A esses tempos, passamos pela escolarização da Educação Infantil, Anos Iniciais, Finais e Ensino Médio. A cada período nos constituímos com uma gama de aprendizados e ocupações.

Atravessamos até o Ensino Superior a possibilidade de estudos técnicos e profissionalizantes que já nos levam ao mundo do trabalho, atestados por legislações que subsidiam a necessidade de trabalhadores para uma sociedade que ainda se estrutura, em sua formação, por uma lista de empregos. Houve o tempo em que as políticas de formação preocuparam-se muito mais em fazer da escolarização um tempo de preparo para o trabalho (BRASIL, 1971). Depois, com a Lei de Diretrizes e Bases da Educação Nacional - LDBEN, vigente, a Lei 9394/96 (BRASIL, 1996), se considerou uma legislação que orientasse e viabilizasse seguir nos estudos, além das condições técnicas de exercer a profissão.

A formação em nível médio, tempo de adolescência para muitos, ainda seria de aprendizados experimentais. É um tempo que tem por propósito chegar a conceitos com uma compreensão que passasse a ser familiar dentro da rede de organização social e política de nossas sociedades. $\mathrm{Na}$ história dos aprendizados e suas didáticas (COMENIUS, 2011) ao aligeiramento da escolarização e conquista dos títulos para a profissionalização, abreviamos um tempo que passa a ser muito mais direcionado aos conhecimentos instrumentais para o trabalho. Não é prioridade pensar para a atuação, posto que é um tempo dividido a informar e levar a um breve estágio, finalizando o tempo desta formação.

Outra proposição é a de contemplar uma formação que prime por conhecer, além de informar, repensando os tempos que ora temos definidos para a titulação que certificamos. Passamos a falar de um contexto que acolhe jovens que pretendem trabalhar no magistério, cheios de vontade de aprender as artes do ofício, mas frenéticos por informações que chegam a todo momento pelas redes sociais! Um tempo que se redefine entre leituras, análises, experimentações e práticas a serem compreendidas em um currículo de formação para estes tempos.

Assim, a formação docente que ainda acontece no Brasil, inicia no Ensino Médio e nem sempre segue pelo Ensino Superior - embora a legislação assim o recomendasse (BRASIL, 1996). Nessa reduzida temporada para a "formação docente", se dará passelivre para a atuação com os Anos Iniciais e a Educação Infantil. Não temos muitos argumentos que sustentam dizer que há formação para a docência quando, num 
reduzido período, se divide o tempo com os conhecimentos que são basilares para a dedicação à leitura de mais autores e compreensão do mundo que nos cerca, em pleno início da adolescência. Este tempo de diálogos e experiências e mais a compreensão das didáticas de sala de aula, tomando a amplitude desta responsabilidade como atuação profissional no ofício de ensinar (GAUTHIER et al, 2013), é muito para tão pouco tempo! Já temos possibilidades físicas e financeiras para a continuidade nos estudos como jovens adultos no Ensino Superior que nos desobrigam abarcar toda essa formação em nível médio.

Entretanto, com a licença adquirida, há uma captura por profissionais que custam muito menos para o desempenho de funções que cumprem até mais horas de trabalho que um profissional, cujo Ensino Superior esteja completo. Aqui já falo de políticas econômicas que não se regram pela qualidade, embora sabendo que a atuação virá a referenciar as bases dos aprendizados desde a primeira infância de muitas crianças!

Acreditamos que a formação profissional que leve a conhecimentos especializados (TARDIF, 2000, p.6), deveria acontecer no Ensino Superior. A importância em compreender a profundidade e responsabilidade em estar difundindo conceitos no aprendizado infantil ou jovem são muito importantes para a vida. Este estudo defende a qualificação da profissão que inicia-se na formação superior, posto que no Ensino Médio cumpre-se uma etapa como aprendiz de conceitos mais para si do que didáticos. A formação docente que acontece no Ensino Médio seria uma opção unicamente válida quando esta formação, não conferindo titulação de professor, fosse indicativo a dar sequência nos estudos para a docência.

A partir deste ponto, argumentamos sobre a formação de professores que atuam, sem a formação apropriada, mas têm a chance de retornar a um curso de licenciatura para a sua formação. E por serem tempos de reconhecer a implicação de todos, políticas governamentais de apoio à formação inicial se colocam à chamar para a qualificação profissional dos professores.

\section{Práticas de uma docência em formação: em busca da qualificação profissional}

O fazer docente se institui no cotidiano de sala de aula pelas experiências e saberes que colocam o professor frente a um coletivo de crianças, cujas técnicas se particularizam ao olhar para cada um, quando coordenam um grupo que tem diretrizes fundamentadas em anos de pesquisas pelas didáticas de sala de aula.

A busca por compreender os fundamentos de um fazer profissional docente nos coloca frente aos estudos epistemológicos da profissão (TARDIF, 2000). Conhecer mais do que forma um conjunto de práticas não instintivas, e que sistematizam saberes tramados entre experiências da vida e muitas áreas de conhecimento que foram já estudadas, respalda as práticas que exercemos. O que temos por uma epistemologia da 
prática profissional "pode ser apreendida através de abordagens desenvolvidas a partir da ação situada em contextos de interação e de intersubjetividade" (CARVALHO; THERRIEN, 2009, P. 129). Segue a definição apresentada pelos autores dizendo que o saber-fazer do professor é

movido pelos seus saberes articulados em vista aos processos de aprendizagem aos saberes da vida no mundo, encontra suporte de análise em referenciais que consideram o fenômeno da cognição nas vertentes desenvolvidas nas ciências sociais com pressupostos antropológicos, sociológicos e/ou psicológicos. (CARVALHO; THERRIEN, 2009, P. 129)

Dos professores que já estavam na sala de aula, mas seus fazeres docentes ainda eram sustentados muito mais pelo empirismo que pela argumentação teórica, o governo buscou os primeiros passos a reverter um quadro ainda muito significativo de professores sem formação para a docência que se ativesse ao trabalho que exerciam: instaurou-se $o$ Parfor por medidas políticas governamentais.

O Parfor - Programa de Ações Articuladas na Formação de Professores da Educação Básica, integrado ao Programa Federal "Plano de Metas Compromisso Todos pela Educação", instituído pelo Decreto no 6.094, de 24 de abril de 2007 (BRASIL, 2007), está vigente ${ }^{5}$. Este foi um dos programas que se somou a vários outros para a melhoria dos índices educacionais no Brasil, especialmente encaminhados desde a Carta Magna, de 1988, em seu art. 124 (BRASIL, 1988), à LDBEN, Lei no 9.394/1996 (BRASIL, 1996) e a promulgação da Lei no 13.005/2014, segundo PNE aprovado por lei (BRASIL, 2014), no Brasil (MIORANDO, 2017, p. 146).

O Programa se dá em regime de colaboração e envolve todos os responsáveis pela gestão, financiamento e participação em espaços que promovam a Educação, que são: a União, por promover a Assistência Técnica e Financeira por meio da elaboração do Plano de Ações Articuladas - PAR, pelo Ministério da Educação, cumprindo as metas do compromisso e a observância de suas diretrizes; os Estados e os Municípios "atuando em regime de colaboração, das famílias e da comunidade, em proveito da melhoria da qualidade da educação básica” (BRASIL, 2007, Art. 1º).

Desde 2009, quando do lançamento deste programa, a meta era qualificar pela formação em primeira ou segunda licenciatura, cerca de 330 mil professores que estão em sala de aula, atuando, mas sem a formação pertinente. $\mathrm{O}$ gerenciamento do Plano é feito pela Coordenação de Aperfeiçoamento de Pessoal de Nível Superior -

5 A fragilidade dos programas que se voltam à qualificação da Educação no Brasil se mostra ainda mais vulnerável desde a medida de congelamento das verbas para a Educação e a Saúde, anunciadas pelo governo Michel Temer, aprovada pela Câmara dos Deputados e o Senado, em proposta de emenda constitucional que cria uma teto para os gastos públicos (PEC 241 ou PEC 55, dependendo da Casa Legislativa), que congela as despesas do Governo Federal, com cifras corrigidas pela inflação, por até 20 anos. (EL PAIS, 13/12/2016, disponível em <https://brasil.elpais.com/brasil/2016/10/10/ politica/1476125574_221053.html> Acesso em 29/12/2017). 
Capes, em parcerias que se firmaram com as Secretarias de Educação dos Estados e dos Municípios, além das Instituições de Ensino Superior - IES públicas ou sem fins lucrativos (MEC, 2011).

As informações mais atualizadas que o Ministério da Educação - MEC anuncia marcam o final de 2016 com 2.890 turmas, em 509 municípios, localizados em 24 unidades da federação. Assim, foram atendidos professores oriundos de 3.282 municípios brasileiros e de 28.925 escolas. Sem contabilizar o ano de 2017, ao final de 2016, o Programa registrou 36.871 professores cursando uma licenciatura e 34.549 formados (CAPES, 2017).

O que percebemos dos dados registrados em torno de 330 mil professores a serem qualificados, como provavelmente meta instituída, e depois de nove anos, 2007 a 2016, atingindo em torno de 35 mil professores, visualizamos 300 mil professores que não foram alcançados! O esforço político pela mudança deste cenário na formação foi muito importante e já faz a diferença para tantas escolas, crianças e municípios. E o que fez brecar esse processo é lastimável!

No dizer de mais uma professora-cursista temos os motivos que a levaram a buscar pela formação pedagógica frente ao que estava encontrando na escola e parecendo não conseguir tramar com suas respostas aos cenários que emergiam. Certamente sua experiência de vida (JOSSO, 2004) a fazia persistir na sala de aula, mas que, sem o apoio de tantos pesquisadores da Educação, se via enfraquecida em compor planejamentos para muitos pontos já pensados nesta área.

\footnotetext{
Os motivos que desencadearam minha busca pelo curso de Pedagogia na modalidade Parfor estão relacionados com a necessidade de refletir acerca da minha prática pedagógica, participando de um espaço onde são proporcionados novos elementos que permitem uma ampliação de olhares no que tange a compreender o distinto contexto, inserido numa comunidade escolar repleta de desafios cotidianos. Esses desafios cotidianos estão ligados ao papel da escola nessa sociedade consumista e que trouxe mudanças profundas nas relações humanas, repercutindo na relação entre professora e alunas/os e na ação pedagógica. (STRAUSS, 2015, p. 11-12)
}

Os desafios que a professora fala atravessam nossa vida na sociedade, e, como ela diz, há um imaginário social (CASTORIADIS, 1982) em que a escola parece ter a função de prestar respaldo a todos: professores, estudantes e familiares, funcionários e equipe diretiva. Daí que as políticas de formação não podem ater-se à formação inicial, mas estar entre outras que ocupam-se a modificar o quadro da Educação com os índices que temos hoje.

Da sua instituição, o Plano Nacional de Formação de Professores da Educação Básica soma-se a outras políticas públicas de governo que, firmadas em parcerias que marcaram uma rede de colaboração entre Estados, municípios, instituições de ensino superior, equipes diretivas nas escolas e professores, os esforços empenham-se 
a qualificar a Educação pela formação do magistério. Dentre as demais políticas, o conjunto forma-se pelo que rege

\begin{abstract}
o Piso Nacional do Magistério, instituído em julho de 2008; os cursos de mestrado profissional para educadores das redes públicas; o Programa Institucional de Bolsa de Iniciação à Docência (Pibid), que visa o aperfeiçoamento e a valorização da formação de professores; o Programa de Consolidação das Licenciaturas (Prodocência), que fomenta a inovação, a elevação da qualidade dos cursos do magistério, a valorização da carreira do professor. (MEC, s/d, Texto Digital)
\end{abstract}

Se reverter o quadro de qualificação profissional tem se mostrado tão difícil, empreender esforços políticos, associados a uma formação que prime pelo cuidado e responsabilidade de seu exercício, é o que precisa estar disseminado nos currículos que os formadores dos formadores têm por base. Há um início que mostrou a possibilidade e a responsabilidade de políticas realizadas em rede. Temos que melhor conhecê-las e nos manifestarmos pelos seu cumprimento ou instauração, quando se escassearem.

\begin{abstract}
Ao final da minha pesquisa, destaco que o Parfor, assim como as Escolas do Campo do município investigado, são experiências muito positivas. Ambos pertencem ao Programa de Ações Articuladas - PAR, e apresentam objetivos comuns: visam a melhorar o trabalho dos professores, na tentativa de oferecer uma boa qualidade de ensino e aprendizagem para os alunos. O cotidiano de cada escola é sempre desafiador e, para alcançar suas metas, cada instituição adota metodologias, procedimentos, ações, dentre outros, que possam contribuir na formação dos alunos para dominarem conhecimentos para viverem no mundo atual como cidadãos participativos, reflexivos, autônomos e responsáveis (TATSCH, 2015, p. 40).
\end{abstract}

Assim como a professora-cursista, há muitas jovens professoras ou monitoras na Educação Infantil que chegam ao Ensino Superior, buscando nas licenciaturas o aprendizado que lhes dará legitimidade para as práticas profissionais. Quando um governo acena para a qualificação na formação dos professores que atuam, mas que não têm a titulação mínima de Ensino Superior, e abre para políticas de apoio, confere outro respeito à Educação que acontece em sala de aula, no campo e na cidade.

A historicidade de suas vidas vêm imbricadas nas linhas políticas que as sociedades assumem ao elegerem seus governantes. A formação para a profissão está em conhecer mais de seus fazeres e pensares, para além de um currículo que se preocupe principalmente com as disciplinas "puras", mas com situações problemáticas concretas (TARDIF, 2000) da profissão.

A busca pela profissionalização emerge da vida que temos a resolver dia a dia. "De fato, no mundo do trabalho, o que distingue as profissões das outras ocupações é, em grande parte, a natureza dos conhecimentos que estão em jogo" (TARDIF, 2000, p.6). Assim, as narrativas que as professoras trazem para as suas aulas em um curso de licenciatura, tornam-se a pauta para a construção de um currículo para a formação. 


\title{
Narrativas de professores em formação inicial: a historicidade de uma vida, a historicidade de uma profissão
}

Os estudos e perspectivas de formação que utilizam as narrativas como suportes para seu trabalho acessam, além do pessoal, o profissional, em um entrelaçamento das duas dimensões. Entendendo o professor como "pessoa", que não separa o profissional do pessoal, mostra-se em atentar para suas trajetórias de vida, para os momentos formativos e o conhecimento que trazem e se configuram relevantes para a formação docente. Como nos aponta Delory-Momberger, para o ser humano, as histórias são o meio para apropriar-se de sua vida. E segue dizendo:

\begin{abstract}
Antes de contar essas histórias para comunicá-las aos outros, o que ele vive só se torna sua vida e ele só se torna ele mesmo por meio de figuraçôes com as quais representa sua existência. A primeira dessas figurações, a mais matricial e abrangente, aquela que de certa maneira enquadra a infinita multiplicação das histórias humanas, concerne ao desenrolar sua vida. Tanto na sua linguagem mais coloquial quanto nas criações mais elaboradas os homens recorrem a palavras e imagens que transpõem para uma representação espacial o desenvolvimento temporal de sua existência: linha, fio, caminho, trajeto, estrada, percurso, circulo, carreira, ciclo de vida (DELORY-MOMBERGER, 2008, p.35).
\end{abstract}

Assim, é narrando suas experiências que os professores (re)significam suas trajetórias de vida; é voltando o olhar para si que permite que criem outras maneiras de ser e estar na vida e na profissão. Para esta reflexão, corroboramos com os estudos de Nóvoa (1995), em que traz uma explanação histórica da profissionalização docente, chamando a atenção para a importância do conhecimento desse processo para o entendimento dos problemas no presente.

Segundo o autor, a profissão docente tem origem no seio de algumas congregações religiosas, que se transformaram em congregações docentes e foram configurando progressivamente um corpo de saberes e técnicas, valores e normas específicas da profissão. Mais adiante, houve a troca do controle da igreja sobre os professores, para a tutela do Estado, sendo a função docente desenvolvida de forma subsidiária e não especializada, resultando em uma ocupação secundária de religiosos ou leigos das mais variadas origens.

A partir do final do século XVIII não é permitido ensinar sem licença ${ }^{6}$, concedida aos sujeitos que preenchem as condições, através de um exame, sendo este fato, decisivo no processo de profissionalização da atividade docente, definindo o perfil e servindo de base para o recrutamento dos professores, delineando, a carreira docente. As lutas travadas nos séculos XIX e XX, com as escolas normais, representaram uma conquista

6 A referência é tomada de Antônio Nóvoa (1995), pesquisador da história da profissão docente da Universidade de Lisboa, Portugal, isto para mostrar a criação de ideia de profissão, mesmo se tratando de professores da escola básica. 
importante do professorado e está na origem de uma mudança sociológica do corpo docente, em que:

As instituições de formação ocupam um lugar central na produção e reprodução do corpo de saberes e do sistema de normas da profissão docente, desempenhando um papel crucial na elaboração dos conhecimentos pedagógicos e de uma ideologia comum. Mais do que formar professores (a título individual), as escolas normais produzem a profissão docente (a nível coletivo), contribuindo para a socialização dos seus membros e para a génese de uma cultura profissional (NÓVOA, 1995, p.18).

Os professores são investidos de um poder simbólico, por serem protagonistas da crença generalizada nas potencialidades da escola, e a profissão exerce-se a partir da adesão coletiva a um conjunto de normas e valores. Foi uma fase importante da profissão docente, pela resposta positiva da sociedade em relação ao seu trabalho. Nasce, com isso, a necessidade de uma identidade profissional, a partir de modelos associativos da época, com histórico de poucos consensos e muitas divisões. Por isso, "a afirmação profissional dos professores é um percurso repleto de lutas e de conflitos, de hesitações e de recuos" (NÓVOA, 1995, p.21).

Porém, o autor em sua obra trata especificamente da formação de professores da Educação Básica, não se referindo aos professores universitários. Mas, se nossa intenção é pensarmos como se instituiu o que é ser professor, como a sociedade entende esse sujeito, como ele mesmo se vê na sua vida e na sua profissão, podemos pensar que esses sentidos e significados são construídos ao longo de toda a sua vida. Estudar não pode estar separado deste cotidiano de vida:

Poder pensar sobre as práticas que realizo na escola, vejo hoje, é a base que fundamenta o fazer pedagógico, cuja qualidade esperamos atingir com sucesso. O curso de Pedagogia - PARFOR foi, para mim, um divisor de águas, por onde consegui enxergar minha profissão de outra forma. Aprendi a valorizar tudo aquilo que eu já fazia em sala de aula, sem nunca saber, tão profundamente, o que estava fazendo. Estudando, percebi a importância disso tudo, das intenções nelas contidas e o que poderia proporcionar para as crianças através do meu trabalho. (MORAES; MIORANDO, 2017, p. 79)

A formação profissional não vista como um peso, mas que sustenta o fazer de uma docência que se compõe cotidianamente, fortalece o professor frente aos desafios que tem pela vida que vive. A sociedade categoriza os indivíduos, ao denominar a profissão, e determina as atribuições de cada cargo, que são construções da própria sociedade, diante das necessidades de cada época:

Dessa forma, a profissionalização é um processo histórico e evolutivo que acontece na teia das relações sociais e refere-se ao conjunto de procedimentos que são validados como próprios de um grupo profissional, no interior de uma estrutura de poder (CUNHA, 1999, p.132). 
Consequentemente, essas determinações são interiorizadas pelos sujeitos, que mesmo antes de entrarem na profissão, já têm instituído uma ideia das dificuldades, da desvalorização social e financeira ${ }^{7}$, da precariedade das condições do espaço físico das escolas, ou seja, como a sociedade determina a profissão professor. Para também compreendermos as escolhas que fazemos, Castoriadis (1987) alerta que "a instituição produz indivíduos conforme suas normas, e estes indivíduos, dada sua construção, não apenas são capazes de, mas obrigados a, reproduzir a instituição". Daí entender o quão livres somos para as mudanças que pretendemos - e não desistimos, resistimos.

As narrativas dos estudantes de licenciaturas e de seus professores levam a perceber os saberes como múltiplos: a cada época surgem novos saberes necessários e novas nomenclaturas vão sendo criadas. A isto salientamos um saber que percebemos intrínseco ao ser professor, o saber pedagógico.

Por tudo isso, posso afirmar que o curso de Pedagogia - Parfor foi de extrema
importância por ter nos dado esta oportunidade de aperfeiçoar nossos
conhecimentos e ter uma maior fundamentação teórica dentro da formação e da
qualificação do ser professor. Essa profissão é desafiadora e exige muito estudo,
preparação, organização, dedicação, persistência, busca, reflexão, observação,
escuta sensível, tendo sempre a criança como ponto de referência. Enfim, o ofício
de ser professor exige muito comprometimento e, acima de tudo, amor pela
profissão. Nesse sentido, as possibilidades apresentadas nesta pesquisa passam
a auxiliar os demais profissionais que atuam na educação, impulsionando-os a
repensarem suas práticas pedagógicas, inspiradas em situações e recursos lúdicos
(HOFSTETTER, 2015, p. 62).

Neste caso, corroboramos com Pimenta e Anastasiou (2010) e Nóvoa (1992, 2009), quando trazem importantes reflexões acerca desta historicidade e formação docente. Historicamente na formação de professores e os diversos saberes necessários à docência foram fragmentados, como as disciplinas: trabalhados de maneira desarticulada, em que uns se sobrepõem aos outros, dependendo do predomínio e status que adquirem na academia em cada época. A isto, "trata-se, portanto, de reinventar os saberes pedagógicos com base na prática social da educação. No caso da formação de professores, com base em sua prática social de ensinar" (PIMENTA; ANASTASIOU, 2010, p.83). Outra fala de uma professora-cursista reforça a potencialidade da reinvenção destes saberes:

Buscando, interagindo, observando, (des)construindo e compartilhando saberes nas aulas do curso de Pedagogia e nos espaços de convivência acadêmica e profissional, posso destacar que é recorrente o discurso sobre a necessidade de se estar em permanente formação para que seja (re)pensada a nossa prática pedagógica. Durante as aulas do curso foram proporcionados diversos espaços de compartilhamento de vivências e experiências pedagógicas que possibilitaram a

7 Mesmo considerando que a profissão docente demanda uma valorização social e financeira, a história da docência mostra que no país ainda não alcançamos essa exigência. Tratando-se do professor universitário, há um reconhecimento e um lugar simbólico diferenciado na sociedade brasileira. 
observação de que mesmo já tendo uma graduação foram sendo conhecidas outras possibilidades de olhares sobre a formação pedagógica (STRAUSS, 2015, p. 12).

Por este viés, não basta saber fazer, precisa ainda, saber ensinar ou entender os conteúdos didático-pedagógicos diretamente relacionados ao campo da atividade profissional e os saberes pedagógicos mais amplos do campo teórico da prática educacional. Com isso, os cursos de formação docente necessitam olhar para a especificidade da formação pedagógica, que antes de refletir sobre o que vai fazer, sobre o que deve ser feito, leva a pensar sobre o que faz. Porém, para tanto, apenas esboçamos uma reformulação na concepção e organização dos próprios cursos, tanto de formação inicial como continuada.

Destas reflexões podemos entender que os saberes, na formação de professores, precisam estar interligados e não fragmentados, pois eles são interdependentes. Neste sentido, juntamente com as questões do ensino, estão a da aprendizagem, que longe de ser vista de maneira dicotômica, esta relação precisa ser de complementaridade.

\section{Docência em Formação: saberes que se agregam ao longo da vida e estudos}

A escrita de uma artigo sempre nos põe a repensar argumentos que já trazíamos, embora nem todos estivessem ditos como aqui se puseram. Rearranjamos argumentos e ideias que vêm represados pelas últimas leituras, debates, resistências. Para este estudo não foi diferente: repassamos pela formação inicial mais uma vez tramada pelos saberes que trazemos, mas tornado coro pelas tantas leituras dos autores aqui trazidos.

Das falas de professores-cursistas da Pedagogia/Parfor, Univates, identificamos em suas narrativas a pesquisa que agora sustenta seus discursos e práticas: a intenção de ensinar não é mais empírica, é experiencial, curricular, disciplinar e da formação profissional. As memórias que remetem à sua vida escolar puderam ser ressignificadas e as professoras autorizadas a um fazer diferente do que viveram: são outros tempos, para outras crianças e uma nova escola.

A formação profissional exige conhecimentos especializados, muito mais aprofundados no Ensino Superior, cuja responsabilidade irá definir a educação de crianças e jovens na sua vida escolar. Alcançamos tempos de infraestrutura e condições econômicas e tecnológicas que não cabem em um período de formação profissional que se basta em nível médio. Esse tempo de conclusão da escolaridade básica está para ser dedicado a qualificar a busca pela profissão que demanda profissionais ainda mais qualificados para a sociedade que construímos.

Ao Ensino Superior compete assumir que há uma grande responsabilidade na formação de professores da Educação Básica. À escola ainda recai parte da função de educar pessoas e a ela cumpre respaldar este processo mediante a pesquisa que ela 
mesma prega a seus alunos. Não está sozinha, mas carece de mais políticas que se somem aos seus esforços.

Para a formação de professores, as políticas estão diretamente imbricadas com a visão de respaldo que o governo dá à Educação. Enquanto a busca pela profissionalização estiver fragilizada pelas prioridades econômicas, imergimos todos em uma sociedade inconstante quanto à Segurança e à Saúde que oferece ao seu povo, o que está diretamente ligado aos índices que revelam a Educação que exercemos.

A historicidade de cada vida dentro da profissão reflete interligações que se mostram pelas narrativas. A história que Nóvoa reconta ao estabelecer a docência como campo profissional, aproxima a compreensão do processo que se consolidou, desculpabilizando os ajustes que ainda não foram feitos. Entretanto, trazemos saberes pertinentes à profissionalização docente para estarmos em contínuo processo de formação, cujos saberes profissionais, experienciais e pessoais se agregam ao longo da vida.

\section{Referências}

ABRAHÃO, Maria Helena Menna Barreto (Org.). Autobiografia e Formação Humana. Porto Alegre: EDIPUCRS, 2010.

BRASIL, Decreto no 6.094, de 24 de abril de 2007. Dispõe sobre a implementação do Plano de Metas Compromisso Todos pela Educação. Disponível em <http://www.planalto.gov.br/ ccivil_03/_ato2007-2010/2007/decreto/d6094.htm>. Acesso em 21/03/2011.

BRASIL. [Plano Nacional de Educação (PNE)]. Plano Nacional de Educação 20142024 [recurso eletrônico] : Lei no 13.005, de 25 de junho de 2014, que aprova o Plano Nacional de Educação (PNE) e dá outras providências. - Brasília : Câmara dos Deputados, Edições Câmara, 2014. 86 p. - (Série legislação ; n. 125) Disponível em <http://www. observatoriodopne.org.br/uploads/reference/file/439/documento-referencia.pdf>. Acesso em $29 / 12 / 2017$

BRASIL. Câmara dos Deputados. Lei no 5.692, de 11 de agosto de 1971. Fixa Diretrizes e Bases para o ensino de $1^{\circ}$ e $2^{\circ}$ graus, e dá outras providências. Disponível em <http://www2. camara.leg.br/legin/fed/lei/1970-1979/lei-5692-11-agosto-1971-357752-publicacaooriginal-1pl.html . Acesso em 22/12/2017.

BRASIL. Constituição (1988). Constituição da República Federativa do Brasil. Disponível em: <http://www.planalto.gov.br/ccivil_03/Constituicao/Constituicao.htm〉. Acesso em: 29/12/2017.

BRASIL. Lei De Diretrizes e Bases da Educação Nacional. Lei no 9.394/1996. Recuperado em: <http://www.planalto.gov.br/ccivil_03/leis/19394.htm>. Acesso em: 22/12/2017.

CAPES, Plano Nacional de Formação de Professores da Educação Básica - PARFOR. Publicado: Terça, 12 Janeiro 2010 09:53 | Última Atualização: Quinta, 24 Agosto 2017 12:44. Disponível em <http://www.capes.gov.br/educacao-basica/parfor>. Acesso em 29/12/2017. 
CARVALHO, Antonia Dalva França; THERRIEN, Jacques. O Professor no Trabalho: Epistemologia da Prática d Ação/Cognição Situada - Elementos para a Análise da Práxis Pedagógica. IN: Revista brasileira de formação de professores. Vol. 1, n. 1, p.129-147, 2009 - ISSN 1984- 5332. Disponível em <http://jacquestherrien.com.br/wpcontent/uploads/2014/06/Professor-no-Trabalho-Epistemologia-da-Pr\%C3\%A1tica-eA\%C3\%A7\%C3\%A3o-Cogn.pdf>. Acesso em 29/12/2017.

CASTORIADIS, Cornelius. A instituição imaginária da sociedade. Tradução de Guy Reynaud. Rio de Janeiro: Paz e Terra, 1982.

CASTORIADIS, Cornelius. As encruzilhadas do labirinto II: os domínios do homem. Rio de Janeiro: Paz e terra, 1987.

CHÈNE, A. A narrativa de formação e a formação de formadores. In: O método (auto) biográfico e a formação/ organização Antônio Nóvoa; Mathias Finger. Natal, RN:

EDUFRN; São Paulo: Paulus, 2010.

Comenius. Didática magna. 4. ed. São Paulo: WMF Martins Fontes, 2011.

CUNHA, M. I. da. Profissionalização docente: contradições e perspectivas. In: VEIGA, Ilma Passos Alencastro; CUNHA, Maria Isabel da (Orgs.). Desmistificando a profissionalização do magistério. Campinas, SP: Papirus, 1999.

DELORY-MOMBERGER, C. Biografia e educação: figuras do indivíduo-projeto. São Paulo: Paulus, 2008.

FLICKINGER, Hans-Georg. A caminha de uma pedagogia hermenêutica. Campinas, SP: Autores Associados, 2010.

FREIRE, Paulo. Pedagogia da autonomia: saberes necessários à prática educativa. 8. ed. Rio de Janeiro : Paz e Terra, 1998.

GAUTHIER, Clermont. et al. Por uma teoria da pedagogia: pesquisas contemporâneas sobre o saber docente. 3. ed. Ijuí: UNIJUI, 2013

HOFSTETTER, Fabiana M. Contribuições do Estágio Supervisionado na Formação de Professores. Monografia de Conclusão de Curso de Pedagogia Parfor. Centro Universitário UNIVATES, 2015.

JOSSO, Marie-Christine. Experiências de Vida e Formação. São Paulo: Cortez, 2004.

MEC, Ministro garante financiamento para formação dos professores. 21/11/2011.

Disponível em: <http://portal.mec.gov.br/busca-geral/211-noticias/218175739/17074-

ministro-garante-financiamento-para-formacao-dos-professores $>$. Acesso em 29/12/2017.

MEC, Plano de formação do professor abrirá 710 vagas de licenciatura, s/d. Disponível em <http://portal.mec.gov.br/component/tags/tag/35038>. Acesso em 29/12/2017.

MIORANDO, Tania M. Trajetos Formativos: Imaginários de Professores Ricos de Saberes. IN: Formação de Professores em Tempos de Incerteza: Imaginários, Narrativas e Processos Autoformadores. BRANCHER, Vantoir Roberto; OLIVEIRA, Valeska Fortes de (Orgs.). Jundiaí, Paco Editorial: 2017. 
MORAES, Sílvia M. MIORANDO, Tania M. Descobrindo um novo mundo: adaptação de bebês na escola. In: MIORANDO, Tania M. et al. (Orgs) Pedagogia(s) contemporânea(s): práticas, espaços e tempos. Lajeado : Ed. da Univates, 2017. Disponível em < http://www. univates.br/editora-univates/publicacao/219>. Acesso em 29/12/2017.

NÓVOA, A. (org.) Os professores e sua formação. Lisboa: Dom Quixote, 1992.

NÓVOA, A. Os professores e as histórias da sua vida. In: NÓVOA, Antônio. (org.) Vidas de professores. Portugal: Porto, 1995.

NÓVOA, A. Professores: imagens do futuro presente. Lisboa: Educa, 2009.

PIMENTA, S. G.; ANASTASIOU, L. G. das. Docência no ensino superior. São Paulo: Cortez, 2010.

STRAUSS, Magali B. Professoras são eternas aprendentes: contribuições do Curso de Pedagogia Parfor do Centro Universitário UNIVATES Lajeado/RS para a prática pedagógica. Monografia de Conclusão de Curso de Pedagogia Parfor. Centro Universitário UNIVATES, 2015.

TARDIF, Maurice. Saberes docentes e formação profissional. 13. ed. Petrópolis: Vozes, 2012.

TARDIF, Maurice. Saberes profissionais dos professores e conhecimentos universitários Elementos para uma epistemologia da prática profissional dos professores e suas conseqüências em relação à formação para o magistério. In: Revista Brasileira de Educação. Jan/Fev/Mar/ Abr 2000 No 13 Disponível em http://www.joinville.udesc.br/portal/professores/jurema/ materiais/RBDE13_05_MAURICE_TARDIF.pdf. Acesso em 18/12/2017.

TARDIF, Maurice; LESSARD, Claude. O trabalho docente: elementos para uma teoria da docência como profissão de interações humanas. 6. ed. Petrópolis: Vozes, 2011.

TATSCH, Andrea. Proposta Pedagógica de Escolas do Campo. Monografia de Conclusão de Curso de Pedagogia Parfor. Centro Universitário UNIVATES, 2015. 